\title{
Humorismo docente o docencia humorística
}

\author{
Dora Bazán Montenegro \\ Universidad Ricardo Palma \\ dorabazanm@yahoo.es
}

\section{Resumen}

El objetivo de nuestro artículo es el estudio lingüístico y metalingüístico del lenguaje que Palma utilizó durante toda su vida y en todas sus obras. Esto dentro de los parámetros sincrónicos, diacrónicos y de los campos fonéticos, morfológicos, sintácticos, semánticos, léxicos, onomásticos, de formas de tratamiento y sobre todo de registro de lenguas científicas y técnicas.

Palabras clave: Registros de lenguas científicas y técnicas, sincrónico, diacrónico, fonético, morfológico, tradiciones de Palma.

\section{Abstract}

The aim in our paper is the linguistic and meta-linguistic study of the language that Palma used throughout his life and in all his works. This within the synchronic and diachronic parameters and in the phonetic, morphological, syntactic, semantic, lexical, onomastic, forms of addressing fields and overall in the scientific and technical language registry.

Keywords: scientific and technical language registry, synchronic, diachronic, phonetic, morphological, Palma's traditions. 


\section{Dora Bazán Montenegro}

Doctora en Educación, Filología Románica, Lingüística y Literatura. Profesora emérita de la Unmsm y directora del Instituto de Estudios Clásicos y Orientales de la URP. 
Palma es fundamentalmente un escritor y, como tal, su estilo se actualiza a través de la lengua escrita. Según la teoría lingüística de Ferdinand de Saussure, los registros de lengua están relacionados con los elementos externos que gravitan más sobre el sistema lingüístico, pero se trata de las vinculaciones del hecho lingüístico con las costumbres y con la cultura de los pueblos. Las conexiones de una lengua con la familia, la escuela, la iglesia y otras instituciones constituyen la lingüística externa que -al influjo de los factores que hemos mencionado- nos permite señalar que, dentro de la existencia concreta de una lengua, es posible observar una variada gama interna de registros y calidades de lengua diferentes. Esto nos permitirá concluir, a nivel de la lengua manejada por Palma, que en el mundo no existe ninguna lengua uniforme ni en la perspectiva vertical (social) ni en la perspectiva horizontal (geográfica) sino que, por el contrario, la diversidad de registros de lengua y de su uso intermezclado, muestra la versatilidad del manejo lingüístico por parte de don Ricardo. Sin embargo, lo que hasta la fecha no habíamos logrado es descubrir que Palma no solo tiene el manejo lingüístico de los registros de lengua sino el conocimiento metalingüístico de los mismos.

Ricardo Palma conocía los diversos registros de la lengua a la perfección y sabía que estos deben usarse con propiedad y de acuerdo con el rango cultural de las personas que los emplean. La tradición El canónigo del taco (Palma, 1964: 1065) es protagonizada por don José Luis Orbegoso, Presidente de la República quien, durante un viaje a la provincia de Jauja, se alojó en la casa del cura del pueblo que había sido su condiscípulo. Sin embargo, la semejanza entre ambos personajes solo llegaba hasta aquí porque, según relata el tradicionista, el convento y el cuartel marcaron la diferencia entre los antiguos condiscípulos. 
Cabe señalar también que esta diferencia observada y destacada por Palma, es de carácter lingüístico, específicamente de diferencias en los registros de lengua. Mientras los acompañantes de Orbegoso (Palma no quiere indicar que también el presidente Orbegoso) empleaban el registro de lengua vulgar, "entre los acompañantes de su excelencia -dice Palma- había algunos militares del cuño antiguo que sazonaban la palabra con abundancia de ajos y cebollas, lo que traía alarmado al pulcro cura de Concepción, temeroso de que se contagiasen sus feligreses y saliesen, a toso y velloso, escupiendo interjecciones crudas". El sacerdote pensaba que esta costumbre debía ser suprimida entre los militares: “(...) una noche en que platicaba íntimamente con Orbegoso, agotado ya el tema de las reminiscencias infantiles, habló el señor Pasquel de lo conveniente que sería dictar ordenanzas penando severamente a los militares que echasen un terno" (Palma, 1964: 1062).

Ante este planteamiento se hace presente la conciencia lingüística de Palma, en este caso en lo referente a los registros de lengua. El tradicionista, a través de las palabras del Presidente Orbegoso, dice:

Rióse su excelencia de las pudibundas alarmas del buen párroco y díjole: Mira, curita, así como a ustedes no se les puede prohibir que digan la misa en latín, lengua que ni el sacristán les entiende, tampoco se puede negar al soldado el privilegio de hablar gordo. Muchas batallas se ganan por un taco redondo echado a tiempo, y para quitarte escrúpulos te empeño palabra de hacerte canónigo del coro de Lima el día que te oiga echar en público un... culebrón retumbante (Palma, 1964: 1067).

El hecho es que, movido por la ambición de la canonjía y sus prebendas, el cura excondiscípulo de Orbegoso se lanzó a decir un feísmo. Pero el registro de lengua normal de un sacerdote no 
es el de un militar y por esto fue sancionado socialmente. En palabras de Palma:

Al siguiente día, con el pie ya en el estribo y rodeado de edecanes y demás muchitanga que forma el obligado cortejo de un presidente republicano, despedíase Orbegoso de su condiscípulo el cura. Este, que había metido largo y resuéltose a ser canónigo, le dijo:

-Con que, José Luis, eso de la canonjía ies verdad o bufonada?

-Lo dicho, dicho curita; pero no hay canonjía sin un taco enérgico. Con que decídete, que el tiempo vuela y hay muchos niños para un trompo.

El señor cura se puso carmesí hasta lo blanco de las uñas, cerró los ojos y exclamó:

-iQué cara... coles! iHazlo, si quieres; sino déjalo! y después de lanzada la tremenda exclamación, el señor Pasquel, escandalizado, asustado del taco redondo que sus sacerdotales labios acababan de proferir, corrió a encerrarse en su cuarto y cayó de rodillas dándose golpes de pecho (Palma, 1964: 1067).

La sanción social no se hizo esperar, debido a que el lenguaje usado por el sacerdote no era el que le correspondía. Dice Palma:

Pero por lo mismo que en el agraciado habían méritos y virtudes que lo hacían digno hasta de la mitra, encontró émulos en sus compañeros de coro que lo utilizaban con el apodo de canónigo del taco (Ibid).

Lo mismo sucede con el lenguaje náutico y de los piratas, del aeronáutico, de la cocina y de las comidas y alimentos, del mobiliario y de la heráldica, del político, literario, administrativo, 
económico, geográfico, histórico, militar, filosófico, lógico, zoológico, botánico, escultórico, pictórico, lingüístico, lexicográfico, hípico, matemático, de artesanía y arte popular, geográfico, esotérico, de gobierno, minero, de gitanos, moros, de diversiones de pulpería, manolas, vestidos y adornos, del lenguaje jurídico y de escribanos, de la caza y la cetrería, del lenguaje médico, del amoroso, religioso.

Innumerables terminologías y registros de lengua, pero, ¿cuáles son las más numerosas? Desde luego que el lenguaje amoroso es manejado con muchísima frecuencia, pero el lenguaje más estudiado, así sea difícil de creer, es el lenguaje religioso. Trata los asuntos terminológicos de dos formas. De una manera lingüística, en la cual tiene seguidores en el mundo entero; y de una forma en que, hasta la fecha, no ha tenido ni tiene imitadores ya que se trata del manejo humorístico de las terminologías sin paralelo en la literatura universal. Para Ricardo Palma, el lenguaje utilizado dependía de las exigencias del tema y de los personajes.

Así, por ejemplo, si el enamorado era un aficionado a la mitología, Ricardo Palma escribía así: “(...) y bien, Mercurio, ¿quién es ella? -le dijo el virrey, que como todos los poetas de su siglo, eran aficionados a la mitología”. (Palma, 1964: 306).

La misteriosa dama sabía que iba a habérselas con un poeta, y para más impresionarlo recurrió al lenguaje de Apolo.

iHola! iHola! -murmuró don Francisco-, Marisadibilla es la niña; como quien dice, Minerva encarnada en Venus. Jeromillo, estamos de aventura. Mi capa, y dame las señas del Olimpo, de esa diosa (Palma, 1964: 306). 
Si era un sacerdote:

Hoy he propuesto a Leocadia, IIevármela a la hacienda; pero ha sido machacar en hierro frío, porque ella, que es argumentadora y más fina que tela de cebolla, me ha salido con la antífona de que, sin licencia del padre Gonzalo, no me seguirá ni hecha cuartos (Palma, 1964: 415).

Si era un escribano:

El escribano llegaba todas las noches a casa de Visitación, y después de notificarla un saludo, pasaba a exponerla el alegato de lo bien probado de su amor. Y así pasaron meses hasta seis, aceptando Visitación los alboroques, pero sin darse a partido ni revelar intención de cubrir la libranza (Palma, Ibid).

Si era un militar:

Bien se barrunta que tan luego como llegó el sábado, y resucitó Cristo, y las campanas repicaron gloria, varió de táctica el galán y estrechó el cerco de la fortaleza, sin andarse con curvas ni paralelas. Como el bravo Córdoba en la batalla de Ayacucho, el capitancito se dijo: iAdelante! iPaso de vencedores! y el ataque fue tan esforzado y decisivo, que Claudia entró en capitulaciones, se declaró vencida y en total derrota.

Las referencias a términos militares abundan, debido a que se ha convertido en un tópico la comparación de la mujer con una fortaleza y la conquista de su amor con el vencimiento de la misma. Palma explota a menudo estas metáforas tradicionales, como cuando compara a la mujer con un campo de batalla; con "inexpugnables fortalezas" y, por extensión, nos habla de "ejércitos auxiliares" (celestinas). 
Son numerosos los textos que contienen términos militares, como: "los rendimientos", "las banderas de parlamento", "las posesiones pacíficas", "los últimos cartuchos", "el izamiento del pabellón" y el "deseo de parlamentar".

Una página en la que sorprendemos, no todos, pero sí muchos de los vocablos antes indicados, es la siguiente:

Tratándose de sitiar fortalezas no había quien lo superase en perseverancia y ardides; mas una vez rendida o tomada por asalto la fortaleza íbase con la música a otra parte, y si te vi no me acuerdo. Baldomero halló en la venalidad de doña Ninfa una fuerza auxiliar dentro de la plaza, y la inexperta joven, traicionada por la inmunda dueña, arrastrada por su cariño al amante, y, más que todo, fiando en la hidalguía del novio, sucumbió ... antes de que el cura de la parroquia la hubiese autorizado para arriar pabellón (Palma, 1964: 808).

Ricardo Palma, con soltura y picardía, utiliza las lenguas especiales de la religión, la náutica y la marina para referirse a la infidelidad de la mujer y a su falta de lealtad: "Al primer barrunto que este [el marido] tuvo de que un cirineo le ayudaba a cargar la cruz...". Del mismo modo, tratando de la falsedad del personaje femenino, relata que un marino, cansado de todo lo relacionado con el mar, decidió casarse con una moza que desconociera hasta lo que era un remo. Cuando la encuentra, se casa con ella, pero he aquí que el mismo día de la boda, la mujer pregunta al marido: "Dime, qué lado es el que me corresponde ocupar en la cama? ¿El de babor o el de estribor?".

El efecto humorístico conseguido por Palma en los ejemplos antes citados, es obtenido también con el empleo de metáforas inspiradas en el lenguaje científico y técnico especializado: 
El señor gobernador era de los que dicen que la mujer en aritmética es un multiplicador que no hace operaciones con un quebrado; en álgebra, la X de una ecuación; en geometría, un poliedro de muchas caras; en botánica, flor bella y de grato aroma, pero de jugo venenoso; en zoología, bípedo, lindo, pero indomesticable; en literatura, valiente paradoja, de poetas chirles; en náutica, abismo que asusta y atrae; en medicina, píldora dorada y de sabor amargo; en ciencia administrativa, un banco hipotecario de la razón y el acierto (Palma, 1964: )

En su libreta de apuntes, copió muchos juegos, algunos de los cuales no incluyó en sus Tradiciones (los juegos aparecen hacia 1870 aunque una década antes encontramos ejemplos de caracterización con el nombre). Quise volver a revisar la citada libreta, pero me fue imposible por lo que me resigno a dejar sin revisar esta cita:

Si a Bolivar la letra con que empieza, y aquella con que acaba le quitamos oliva de la paz símbolo hagamos, esto quiere decir que del tirano la cabeza y los pies cortar debemos si es que una paz durable apetecemos.

Ricardo Palma recurre al significado de la segunda mitad del nombre y también a la contaminación: "Salimos de Guatemala y entramos en Guate-peor; cambia el pandero de manos, pero de sonidos, no". (Palma, 1964: 54)

A veces no interesa repetir un sonido ni un grupo de sonidos y tampoco se quiere fusionar dos nombres sino que simplemente se desea transcribir nombres más o menos estrambóticos como los de estas exclamaciones: San Expedito y la Virgen de la buena leche, Santa Orofrisia, virgen y mártir, Santa Tecla, abogada de los pianos roncos. Aunque muy escasos, también existen ejemplos en los que se combina el valor asociativo del sonido de los 
nombres de pila con la rima. En cierta oportunidad, el alguacil mayor se alejó murmurando: "-Coces de yegua, amor para el rocín, iSanta Librada! ¿Si será la salida como la entrada?” (Palma, 1964: 532).

Por otro lado, la derivación no etimológica, vale decir la de los nombres propios, constituye también un valioso instrumento de juego. El tradicionista nos habla así de "la niñería de Niño" (Palma, 1964: 114), de la sentencia del juez para que Núñez Romero "fundase un romeral de chicos" (Palma, 1964: 309), de que ni "siquiera el italiano Ton ti había descubierto las pólizas tontinas o para tontos" (Palma, 1964: 197) y que “(...) en un festín dado por doña Bárbara de la Calzada, (...) improvisó el santo sacerdote el siguiente brindis, (...): Bárbara del barbarismo, entre las bárbaras, bárbara. Tu afectísimo capellán. Poniendo punto a las barbaridades del vicario" (Palma, 1964: 595-6).

El significado que se insinúa en los ejemplos anteriores adquiere mayor importancia cuando se destaca la analogía que existe entre los homónimos: "Un oidor que estaba cercano, dizque oyó a fuer de buen oidor” (Palma, 1964: 759) Y “el padre Ojeda ojeó y hojeó el libro" (Palma, 1964: 253). Del mismo modo, cuando se insiste en el contraste de los homófonos: Que ni Vera-Cruz es cruz, ni Santo Domingo es santo, ni Puerto Rico es tan rico como lo ponderan tanto (Palma, 1964: 927).

De otro lado, se relaciona uno de los homófonos con la conducta o con el carácter del otro. Palma nos dice que Picado se sintió como su nombre, picado, (Palma, 1964: p. 56) Y nos cuenta que:

Acaso por esas quisquillas se despertó el encono de la gente de claustro contra el virrey Manso; pues un fraile, predicando el sermón del Domingo de Ramos, tuvo la insolencia de decir que Cristo había entrado en Jerusalén montado en un burro manso (Palma, 1964: 568-9)". 
Honra tu nombre, pues honrarlo puedes pródiga para mí siendo en mercedes (A Mercedes, Filigranas: 284).

Avilés consagraba gran parte de su tiempo a las prácticas religiosas. El pueblo lo pintaba con esa frase. En la oración hábil es y en el gobierno inhábil es (Palma, 1964: 822).

Cuando se desvaneció el peligro, todos aquellos concurrentes se fijaron en la cortina, y con terror vieron que las llamas habían consumido las seis primeras letras de la inscripción, respetando las que forman esta palabra: iASUSTA! (Palma, 1964, p. 1074-75).

Por último, cabe insistir en que el empleo del calambur no es buscado inconscientemente; nuestro autor, lo sabemos bien, conoce los recursos que utiliza:

Dizque los padres crucíferos de San Camilo andaban aburridos con el prelado, que a mañana y tarde les hacía servir en el refectorio un guisote conocido con el nombre de chanfaina (...) Llegó la época de elecciones, y uno de los aspirantes ganó el capítulo sólo por haber dicho: "Si triunfo, la chanfaina se quita. A esto se refiere el vítor:

Dios, con su pródiga mano, nos redimió en nuestra cuita, iVítor el padre Otiliano, que la chanfaina nos quita!

y cumplió al pie de la letra su paternidad con el compromiso; pues si el antecesor suministraba la chanfaina con caldo, el nuevo prelado eliminó este, dando por descargo a los que le reconvenían que él no había ofrecido suprimir la vianda, sino darla sequita, esto es, sin caldo. Digan que el castellano no admite calembour" (Palma, 1964: 301-2). 
El deseo de Palma estriba en que se recuerden cada uno de los homónimos que intervienen en el retruécano y para ello selecciona los vocablos, las situaciones, etc.

Llamado el marqués a declarar, dijo que era cierto que se había encontrado en medio del barullo; pero que, lejos de echar leña a la hoguera, no había hecho más que llamar a su mayordomo para ordenarlo que aquietase los ánimos.

-Mala manera de aquietar -arguyó el juez, empleaba su señoría gritando imata!, imata!, imata!

-Es claro, señor juez; yo llamaba a mi mayordomo.

-iPara mi santiguada! ¿No es Juan Pastrana el mayordomo de su señoría?

-Exacto, señor juez; exacto, Juan de Mata Pastrana..., y lo mismo da para mi llamarlo por su apellido que por cualquiera de los nombres. No es culpa mía que los negros hayan confundido con una orden lo que no era sino un llamamiento (Palma, 1964: 597-8).

Y ya dentro de este torbellino, el humorismo de Palma se desborda, nada lo detiene; juega con los nombres, con los apellidos, con todo lo que está a su alcance, con todo lo que en otro momento le servía de tema de reflexión y de estudio:

Tratábase de cristianar a un niño, y antes de IIevarlo al bautisterio, el cura apuntaba, en la sacristía, los datos que consignaría más tarde en el libro parroquia!

- ¿Qué nombre le ponemos al chico?

-Por mí -contestó al padrino-, póngale usted Tigre. 
-No puede ser-arguyó secamente el párroco.

-Pues entonces, póngale usted Búfalo o Rinoceronte.

-Tampoco puede ser. Esos son nombres de animales y no de cristianos.

-iNo moje, padre! ¿Cómo el Papa se llama León?

Al hombre de sotana y birretillo no se le ocurrió, por el momento, otra contestación que ésta:

-Ya he dicho que no puede ser, soy camanejo y no cejo.

-Pues yo soy de armedo y no cedo, y el mamón, continuó morito (Palma, 1964: 1435).

El primer dato y el más seguro acerca de que Ricardo Palma estudió latín, lo obtenemos de una de las poesías de su primer libro, Filigranas. De otro lado, los documentos de la época acreditan que Ricardo Palma perteneció a una de las generaciones que aprendió latín en secundaria, pese a que, por el atraso de la metodología, "casi nada aprendían”, según dice. Del análisis de los programas que se encuentran en el colegio Guadalupe, puede colegirse que la enseñanza del latín era puramente gramaticista, estática, y que no existía la participación activa del alumno. Pero, al final del curso, trabajaban las fábulas de Fedro y algunos textos de Cicerón u Horacio. Por todo lo dicho, y por otras razones, el tradicionista anotó:

"Preguntaba un chico al autor de sus días:

-Papá, ¿qué cosa es el latín? -Y su padre respondió:

-Una cosa que se aprende en tres años y se olvida en tres días". 
Sin embargo, y a pesar de la opinión del autor de las Tradiciones, a través de ellas y de sus demás obras, "el uso correcto de la lengua del Lacio" aparece muy a menudo.

El latín es usado por Palma no solo en los casos anteriores, sino que, al mismo tiempo, se vale de él para dar rienda suelta a su humorismo. Hablándonos de una competencia verbal entre Echegaray y Larriva, nos cuenta que el primero, tomando el pie de cita de Larriva, le dice:

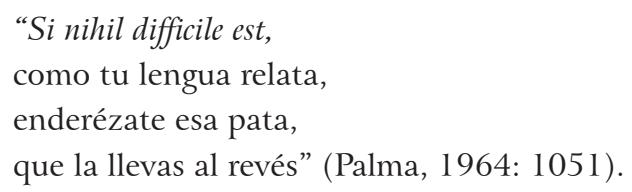

Ante la clara alusión de Echegaray, Larriva contesta con esta otra cuarteta:
"Cuando Dios hizo esta alhaja, tan ancha de vientre y lomo
no dijo:-Faciamus horno, sino:-Faciamus tinaja" (Ibid).

Si bien Palma no puede deducir cuál de las improvisaciones es la mejor, porque "La lucha fue de bueno a bueno, de potencia a potencia, de gallo a gallo" (Ibid), nosotros podemos concluir que Echegaray se expresaba en un correcto latín (quizás por tratarse solo de repetir el verso que le dio Larriva).

En cambio, en las formas verbales, se usa el presente en vez del futuro (en la repetición del verbo). Claro que aquí, Palma debió pensar en la rima antes que en la corrección, pues no sería posible el retruécano de haber escrito ibitis, en vez de itis, o canes, en vez de canis. 
Finalmente, el tradicionista quiere recordar y enseñar latín. Lo hace con dos frases frecuentes en la antigua misa católica y con eso destaca la agilidad mental de la limeña:

"(que era) de las que cuando oyen el Dominus vobiscum, no hacen esperar el et cum spiritu tuo” (Palma, 1964: 581).

En otra referencia cita el Agnus Dei qui tollis peccata mundi (cordero de Dios que quitas los pecados del mundo), del que se sirve para el memorialito que, según él, "dirigieron a un obispo, dos mujeres a quienes el nuevo cura de la parroquia suprimió de improviso el pago de una pensión alimenticia que su antecesor, para apartarlas del pecadero, las había asignado sobre el producto del cepillo de las ánimas":

"Ilustrísimo señor:

Era el cura anterior un agnus Dei;

pero puesto que el nuevo es un qui tollis

y no es posible ya peccata mundi,

señor obispo, miserere nobis" (Palma, 1964: 413).

Otro caso en que el tradicionista no citó la fuente de sus frases latinas es el diálogo que aparece en El latín de una limeña:

"El poeta perdió los estribos y la lengua se le enlatinó, diciendo a la joven:

-Háblame niña, con pausa.

¿Estas triste? ¿Quare causa?”

y Mariquita, recordando el latín que había oído al capellán de las clarisas, le contestó rápidamente:

Tristis est anima mea

hasta que la saya vea $(. .$. 
El amartelado poeta, viendo que la muchacha ponía el dedo en la llaga, tuvo que formular esta excusa que, en situaciones tales, basta para cortar el nudo gordiano:

-"Et quare conturbas me si sabes que no hay con qué?

-A lo que la picaruela demoledora de corazones, mostrando el camino de la puerta, le dijo:

Entonces, fugite, in alia, que otro gato dará algalia" (Palma, 1964: 630).

La fuente en que Palma se basó para escribir los dísticos antes citados es -cosa increíble- un salmo de lamentación o de súplica:

Quare tristis es, anima mea?

Et quare conturbas me?

Spera in Deo, quoniam adhuc confitebor illi salutare voltus mei

et Deus meus (Ps. 4, 6, 7) (cf. ps. 42, 5).

Sorprendente y reconfortante es esta forma de presentar el conocimiento del patrono de nuestra universidad. Sin embargo el afán docente de Palma y su humorismo docente se encuentran implicados de tal forma que no es posible hablar con propiedad de un humorismo docente y tampoco de una docencia humorística. 


\section{Bibliografía}

Bazán, D. (2001). Mujeres, ideas y estilo en las tradiciones de Palma. Lima: Editorial Universitaria, Universidad Ricardo Palma.

Beigbeder, O. (1968). La simbología. Barcelona: Oikos-Tau S.A.

Castagnino, R. (1965). Análisis Literario. Buenos Aires: Editorial Nova.

Compton, M. (2000). Obra poética de Ricardo Palma. Lima: Biblioteca Nacional del Perú.

Criado De Val, M. (1962). Fisonomía del idioma español. Madrid: Aguilar.

De Saussure, F. (1954). Curso de lingüística general. Buenos Aires: Editorial Losada.

Díaz, J. (2015). Cronología de las Tradiciones Peruanas. Lima: Editorial Universitaria, Universidad Ricardo Palma.

Díaz, J. (2015). Tradiciones olvidadas. Lima: Editorial Universitaria, Universidad Ricardo Palma.

Havelock, E. (1986). La musa aprende a escribir. Barcelona: Editorial Paidós.

Lázaro, F. (s/f). Curso de Lengua Española. Buenos Aires: Manual de Orientación Universitaria.

Le Guern, M. (s/f). La metáfora y la metonimia. Madrid: Ediciones Cátedra.

Marchese A. y Forradellas, J. (1989). Diccionario de retórica, crítica y terminología literaria. Barcelona: Ariel S.A. 
Miranda, L. (1993). Curso de lingüística general. Lima: Editorial San Marcos.

Miranda, L. (2002). Introducción a la lingüística del texto. Lima: Editorial Universitaria, Universidad Ricardo Palma.

Náñez, E. (1973). El diminutivo. Madrid: Editorial Gredos.

Palma, R. (1964). Tradiciones Peruanas completas. Madrid: Ediciones Aguilar.

Pérez, C. (2015). Liberalismo Criollo: Ricardo Palma, Ideología y política (1833-1919). Lima: Editorial Universitaria, Universidad Ricardo Palma.

Piero De La Luca, M. (1963). Didáctica de la lengua oral. Buenos Aires: Kapelusz.

Sidman, M. (1978). Tácticas de investigación científica. Barcelona: Editorial Fontanella.

Spang, K. (1979). Fundamentos de retórica. Pamplona: Ediciones Universidad de Navarra S.A.

Tanner, R. (2005). El humor de la ironía y la sátira en Las tradiciones peruanas. Lima: Editorial Universitaria, Universidad Ricardo Palma.

Tanner, R. (2009). Aproximaciones al estudio de las tradiciones peruanas. Lima: Editorial Universitaria, Universidad Ricardo Palma.

Von Kutschera, F. (s/f). Filosofía del lenguaje. Madrid: Gredos.

Vossler, K. (1959). Espíritu y cultura en el lenguaje. Madrid: Ediciones Cultura Hispánica. 